\title{
Retraction Note: Rainfall trend based on computer image system and English translation of tourist attractions in coastal cities
}

\author{
Xiaowei Zou ${ }^{1}$
}

Published online: 11 November 2021

(c) Saudi Society for Geosciences 2021

Retraction Note to: Arabian Journal of Geosciences (2021) 14: 1014 https://doi.org/10.1007/s12517-021-07357-z

The Editor-in-Chief and the Publisher have retracted this article because the content of this article is nonsensical. The peer review process was not carried out in accordance with the Publisher's peer review policy. The author has not responded to correspondence regarding this retraction.

The original article can be found online at https://doi.org/10.1007/ s12517-021-07357-z.

Xiaowei Zou

zouxiaowei2004@163.com

1 School of Humanities \& Social Sciences, Heilongjiang Bayi Agricultural University, Daqing 163319, Heilongjiang,

China 